\title{
Juventudes no ensino médio: sentidos atribuídos à escola e aos planos de futuro.
}

\section{Rosemeire Reis ${ }^{1}$}

Resumo: Neste artigo apresentamos reflexões sobre os sentidos atribuídos à escola média e aos planos de futuro para jovens não favorecidos economicamente e, em especial, para jovens do vespertino de uma escola pública estadual de Ensino Médio em Maceió. Neste texto trazemos à tona os resultados de alguns estudos e aspectos identificados no questionário, no grupo de discussão e inventários de saber realizados em um estudo de caso (pesquisa quanti-qualitativa). Pode-se identificar nos estudos sobre jovens não favorecidos economicamente que a escola média é importante para suas vidas, mas, segundo eles, esta escola não cumpre a promessa de prepará-los para um futuro melhor, que na maioria dos casos está atrelada a possibilidade de entrar na universidade. Eles não reconhecem na escola média espaços de diálogo para pensar seus planos de futuro e recorrem em primeiro lugar à família para tratar desta questão. Compartilhamos os questionamentos apresentados em outras pesquisas sobre a necessidade de se pensar na possibilidade de espaços de diálogo com os jovens desfavorecidos economicamente na escola média para que estes tenham condições de articular o que aprendem nesta etapa de escolarização com a construção de possíveis táticas e estratégias para viabilizar seus planos de futuro.

Palavras-chave: Juventudes; Ensino Médio; escola; plano de futuro

\footnotetext{
1 professora de graduação e pós-graduação na Universidade Federal de Alagoas (UFAL), doutora em Educação pela Universidade de São Paulo (USP), sob a orientação da Profa. Dra. Helena Coharik. Chamlian, e realizou pós-doutorado pela Universidade Federal de Sergipe (UFS), sob a supervisão do Prof. Dr. Bernard Charlot. Líder do grupo Juventudes, Culturas e Formação (UFAL) e integrante do grupo Profissão Docente: desafios contemporâneos (USP). As áreas de interesse em relação à pesquisa são: Juventudes, pessoas adultas e Escolarização, condição juvenil, relação com o saber e com os saberes, Ensino Médio, formação de professores, autobiografia e formação.

Endereço: R. Projetada, 140, Conjunto Res. Vaticano, Ed. Gregório I, apto 601, Mangabeiras, Maceió, AL. Tel: (82) 9948-1132, rosemeirerreis@yahoo.com.br
}

Latitude, vol. 6, $\mathrm{n}^{\circ} 1$, pp.131-155, 2012

DOI: https://doi.org/10.28998/2179-5428.20120109 
Juventudes no ensino médio: sentidos atribuídos à escola e aos planos de futuro.

\begin{abstract}
In this paper we reflect on the senses attributed to high school and future plans for low-income young students, particularly those attending afternoon classes in a state public high school in Maceió. Here, we highlight the results of some studies and aspects identified in the questionnaire, discussion group, and knowledge inventory performed in a case study (a quantitative-qualitative research). Studies have shown that high school is important for low-income students, but, according to them, it does not keep the promise of preparing them for a better future, and this is, in most cases, related to the possibility of entering a university. Students claim that high school does not open space for dialogue on their future plans and, therefore, they have to seek family help regarding this issue. We share questions shown in other researches on the necessity of a dialogue space with low-income high school students so that they can articulate what they learn in this school phase with the construction of possible tactics and strategies to make their future plans feasible.
\end{abstract}

Keywords: youths; high school, school, future plan

\title{
Introdução
}

Neste artigo apresentamos reflexões sobre os sentidos atribuídos à escola e aos planos de futuro para jovens não favorecidos economicamente do Ensino Médio e, em especial, para jovens/estudantes do vespertino de uma escola pública estadual de Ensino Médio em Maceió. Os resultados da pesquisa de campo foram obtidos do recorte de um estudo maior, denominado "Estudantes da escola pública estadual do Ensino Médio em Maceió: quem são, os sentidos que atribuem aos estudos, as possíveis relações entre a experiência escolar e seus planos de futuro (2010-2012), no âmbito do grupo de pesquisa "Juventudes, Culturas e Formação".

A pesquisa mais ampla analisou os aspectos constitutivos da vida dos estudantes que são, em sua maioria, jovens e em menor parte adultos estudantes do noturno. Investigou ainda os sentidos que estes atribuem à escola e aos estudos. O referido estudo tratou-se de um estudo de caso (pesquisa quanti-qualitativa), com uma "abordagem local". Segundo Van Zanten (2001), esta abordagem pressupõe uma concepção de espaço local 


\section{Rosemeire Reis}

como um 'site', "[...] uma construção social dotada de certa coesão interna e de uma autonomia relativa em relação ao centro, suas ao mesmo tempo, estruturalmente articulada a ele por uma relação de dominação $e$ interdependência" (VAN ZANTEN, 2001, p. 19). Esta perspectiva de investigação se apoia no intercruzamento de dados dos diferentes procedimentos de pesquisa.

$\mathrm{Na}$ primeira fase da pesquisa, realizamos um estudo exploratório com a aplicação de duzentos e dezoito questionários respondidos por jovens do vespertino (cento e quinze estudantes) e jovens e adultos do noturno (cem estudantes). Não conseguimos saber se os outros três eram do noturno ou diurno porque deixaram a questão sobre o turno em que estudam sem responder. Neste artigo apresentamos os resultados dos cento e quinze questionários respondidos pelos jovens do Ensino Médio do vespertino, do primeiro, segundo e terceiros anos. O questionário foi composto por cinquenta e cinco questões com o objetivo de realizar um levantamento geral de aspectos da vida, do trabalho, das práticas culturais dos estudantes (vinte e três questões) e também de sua relação com a escola e com os estudos (vinte e sete questões). Com os dados tabulados foram construídas as tabelas e gráficos que estão sendo analisados por equipes, integrantes do grupo de pesquisa. Para o tratamento dos dados foi utilizado o programa PSPP que é "um software livre disponibilizado para análises estatísticas sobre matrizes de dados. Permite gerar relatórios tabulados, normalmente utilizados na realização de análises descritivas e inferências a respeito de correlações entre variáveis." (GNU-PSPP, 2010 apud SANTOS, 2011, p. 97).

No sentido de aprofundar a compreensão sobre as questões foram organizados grupos de discussão, um no vespertino e outro no noturno. Ocorreram dois encontros com cada grupo de discussão, em outubro e novembro de 2011, com o objetivo de debater alguns aspectos nos gráficos elaborados a partir dos questionários. Os estudantes elaboraram também, inventário de saber, um instrumento criado e aprimorado por Charlot (1996, p.51) e por sua equipe de trabalho. Tinha como modelo de pergunta: "Desde que nasci aprendi muitas coisas, em minha casa, no bairro, na escola e noutros sítios [em outros lugares]. O quê? Com quem? Em tudo isso o que é mais importante para mim? E agora o que estou à espera?" (CHARLOT, 2009a, p. 18). Porém, por algum equívoco, a questão que foi respondida pelos estudantes ficou mais resumida: "Desde que

Latitude, vol. 6, n¹, pp.131-155, 2012. 


\section{Juventudes no ensino médio: sentidos atribuídos à escola e aos planos de futuro.}

nasci aprendi muitas coisas; em casa, no bairro, na escola, em muitos lugares. O que ficou de mais importante? E agora, o que espero aprender?". Esta formulação de questão não reforça que os estudantes precisam descrever o que consideram ter aprendido e onde tal omissão pode ter interferido nas respostas, deixando os textos com menos detalhes sobre estas questões. De qualquer modo, os estudantes descreveram minimamente o que consideram ter aprendido e principalmente focalizaram as aprendizagens interpretadas como mais importantes, como também descreveram o que esperam aprender. Neste artigo apresentamos brevemente o que os estudantes do vespertino dizem sobre o que esperam aprender ao término do Ensino Médio.

No primeiro encontro do grupo de discussão, foram priorizados aspectos da vida, lazer, trabalho, sociabilidade etc., e, no segundo, foram focalizadas as questões relacionadas à escola, aos estudos e aos planos de futuro. Estes encontros foram realizados, tendo como referência os pressupostos do "grupo de discussão", conforme Weller. Segundo a autora, estes grupos "se constituem como representantes de estruturas sociais, ou seja, de processos comunicativos nos quais é possível identificar um determinado modelo de comunicação" (WELLER, 2006, p. 246). Tal procedimento de pesquisa privilegia a apreensão de experiências coletivas como características sociais do grupo pesquisado, proporcionando a reconstrução dos contextos sociais e dos modelos que orientam as ações dos pesquisados. A autora argumenta que o grupo de discussão permite apreender o diálogo mais próximo da realidade do grupo e captar detalhes do convívio do grupo, por pertencer ao mesmo meio social, por privilegiar o diálogo interativo entre os participantes; diminui-se, assim, a interferência do entrevistador no grupo, já que os estudantes estão entre colegas de mesma faixa etária.

Cada encontro foi iniciado com uma questão mais ampla que permitiu a discussão entre os participantes. Posteriormente, alguns gráficos com resultados de questões do questionário foram utilizados para fomentar o diálogo no grupo. No primeiro encontro, foram selecionadas questões relacionadas à primeira parte dos questionários, que focalizava aspectos da vida fora da escola, espaços de lazer, condição social e econômica e, no segundo encontro, as questões focalizadas diziam respeito à segunda parte do questionário, com aspectos relacionados à relação com escola e com os estudos. Houve dificuldades nas transcrições 
do segundo encontro em razão do barulho que ocorria fora da sala de aula onde estavam realizando o trabalho.

Apresentamos a seguir, de onde parte nosso olhar para a questão dos sentidos atribuídos pelos jovens à escola e aos planos de futuro e uma breve análise de alguns aspectos identificados nos questionários, grupo de discussão e inventários de saber realizados com os estudantes do vespertino de uma escola média em Maceió sobre estas questões.

\section{1-A construção de nosso olhar para os jovens do Ensino Médio}

Em consonância com os estudos da Sociologia da Juventude, na tese de doutorado, denominada "Encontros e desencontros: a relação de jovens alunos do ensino médio com os saberes escolares", realizada entre 2002 e 2006, passamos a investigar os estudantes de ensino médio não apenas como "alunos", mas como "jovens", considerando a juventude como categoria sociocultural não homogênea. Os estudos de autores como Dayrell (2007, 2009), Abramo (1997), Peralva (1997), Pais (1993), ratificam o nosso entendimento de que as juventudes são plurais e que elas se constroem, em grande parte, dentro de instituições escolares. Portanto, torna-se necessário "compreender suas práticas e símbolos como manifestação de um novo modo de ser jovem, expressão de mutações ocorridas no processo de socialização" (DAYRELL, 2007, p.1107).

Estas manifestações são produzidas através da mescla entre faixa etária, gênero, condições de moradia, renda familiar, mundo do trabalho, vida escolar e formas de sociabilidades diversas. Nessa direção, o contexto escolar tem sido privilegiado como lugar de expressão de uma multiplicidade de modos de ser jovem, que não correspondem a um modelo de sujeito definido apenas por idade, e sim, por uma composição plural, que inclui dimensões históricas, culturais, econômicas e políticas.

Portanto, já nesta pesquisa nossa intenção era a de conhecer um pouco os jovens que frequentam o Ensino Médio nesta perspectiva mais ampla, analisar a construção destes sujeitos como alunos, sua relação com a escola e com os estudos. Buscamos, portanto, estratégias de aproximação, tanto da escola, quanto dos jovens estudantes desses três anos finais da Educação Básica.

Investigamos alunos de uma escola pública de ensino médio, que no passado tinha prestígio e atendia as elites das camadas médias e hoje

Latitude, vol. 6, n¹, pp.131-155, 2012. 


\section{Juventudes no ensino médio: sentidos atribuídos à escola e aos planos de futuro.}

atende, em grande parte, jovens da periferia da zona sul de São Paulo. As famílias desfavorecidas e de camadas médias pobres buscam nesta escola uma estratégia possível para dar uma boa oportunidade de escolarização para seus filhos. Geralmente os pais dos alunos trabalham fora, residem em bairros considerados violentos, sem opções culturais e de lazer. Principalmente as famílias dos jovens/alunos do período diurno recorrem a esta escola e a cursos extracurriculares para permitir uma moratória breve aos filhos, ao menos até o final do ensino médio. Além de outros aspectos que analisamos na referida pesquisa podemos afirmar que uma grande parte dos jovens investigados apresentava inquietações sobre o que fazer após o ensino médio, um desejo de encontrar um emprego que possibilite condições para que possam realizar seus projetos futuros e dúvidas sobre como atingir seus objetivos. É importante ressaltar que chamou a atenção a angústia de boa parte dos jovens em relação à falta de espaços para discutir, refletir sobre aspectos relacionados a possíveis oportunidades de continuidade de estudos e de trabalho após o ensino médio. Esses resultados corroboram com o estudo de Manzano (2004), integrante do grupo de pesquisa sobre "a escuta ao aluno do ensino médio". Para muitos deles essa instituição deixa a desejar, especialmente para os alunos que estão terminando o ensino médio. Saem dessa etapa de escolarização sem informações básicas sobre as profissões, sobre os cursos de nível superior, sobre cursos técnicos e de cursinhos preparatórios para o vestibular e outras informações que poderiam ajudá-los. Identificamos naquele estudo que a escola, de maneira geral, não se envolve com o momento complexo e difícil que esses jovens estão vivenciando. Identifica-se que grande parte dos jovens procurava construir praticamente sozinhos as estratégias para viabilizar seus planos de futuro. As questões analisadas no doutorado foram identificadas também quando trabalhamos na avaliação de um projeto denominado "Pró-Universitário", uma parceria entre a FEUSP e Secretaria de Educação do Estado de São Paulo, que pretendia propiciar um curso de preparação para os jovens da zona leste de São Paulo, que gostariam de ingressar na universidade. Neste projeto alguns professores da USP preparavam materiais e os estudantes graduandos dos cursos de licenciatura realizavam uma formação após o horário das aulas.

A partir de questionários e entrevistas com jovens do Ensino Médio de escolas da zona leste de São Paulo identificamos que tinham poucas 
informações sobre o que é uma universidade, os tipos de universidades e de cursos que existem, sobre espaços culturais gratuitos, sobre cursos técnicos públicos ou privados. O projeto de modo geral sofreu críticas dentro da universidade e de parcela de professores da escola pública, porque os estudantes da universidade estariam, sem formação docente, atuando como professores. Para estes o governo estadual deveria melhorar as condições de trabalho dos professores para que o Ensino Médio público pudesse melhorar e inclusive preparar seus estudantes para uma universidade como a USP.

Mesmo concordando com tais argumentos, identificamos também um aspecto interessante. Estes jovens, em sua maioria, elogiavam esse projeto porque os "monitores", que eram alunos das graduações da Universidade de São Paulo, discutiam com eles as questões de seus projetos de futuro, apresentavam opções culturais, informações sobre cursos e profissões e, também, porque eles se espelhavam na trajetória de estudos dos jovens monitores. Afirmavam que se esses monitores, que muitas vezes tinham estudado em escola pública tinham conseguido entrar na USP, eles também poderiam sonhar com esta possibilidade.

Também consideramos relevante a pesquisa denominada "Que Ensino Médio queremos", realizada pela "Ação Educativa" no âmbito do Projeto "Jovens Agentes pelo Direito à Educação" e coordenada por Ana Paula Corti aproxima-se de nosso interesse de investigação. Esta pesquisaação teve como objetivo promover uma reflexão coletiva com diferentes sujeitos da escola pública (estudantes, professores, equipes técnicas e familiares) a respeito dos sentidos e significados do ensino médio, e de qual deve ser o rumo das políticas para este nível de ensino. Tal estudo teve uma etapa quantitativa envolvendo 880 estudantes e, uma segunda etapa qualitativa, que mobilizou 177 pessoas de cinco escolas estaduais da zona leste para aprofundar a discussão sobre "o ensino médio que queremos" em oito grupos de diálogo.

Conforme Corti (2001), os resultados mostraram que os aprendizados vistos como os mais necessários pelos jovens, nesta fase da vida, estão relacionados à própria construção da condição de estudante, mostrando que eles esperam que a escola os motive mais para o estudo e desenvolva neles os hábitos e atitudes necessários para aprender. Outro destaque é que os jovens demandam conhecimentos sobre o mercado de trabalho, sobre as diferentes profissões e alternativas no ensino superior, como algo 
Juventudes no ensino médio: sentidos atribuídos à escola e aos planos de futuro.

necessário para se inserirem após o ensino médio. Explica que existe uma forte demanda por uma escola que proporcione a reflexão sobre o mundo do trabalho e propicie um processo de orientação profissional; um ensino médio que permita o delineamento de projetos profissionais, incluída aí a escolha de cursar o ensino superior.

De modo geral, estes estudos nos levam a problematizar qual o lugar e os limites da escola média em relação às necessidades, angústias e perspectivas de futuro dos jovens de grupos sociais não favorecidos que passam a dela fazer parte.

2- Sentidos da escola média e os planos de futuro na perspectiva destes jovens.

Para compreender a atribuição de sentidos à escola e aos planos de futuro pelos jovens partimos do pressuposto de que é necessário analisar como se opera a conexão entre sujeito e saber, conceber esse sujeito como um ser desejante e social (CHARLOT, 2000), bem como tratar essa conexão a partir de uma perspectiva dialética entre sentido e eficácia, pois o sujeito apropria-se de um saber que lhe é exterior, que lhe faz sentido, o que exige determinadas atividades; além disso, ele reelabora tal saber internamente, de acordo com suas referências anteriores (LEONTIEV, 2001). São as atividades do sujeito que possibilitam a apropriação dos saberes. ((LEONTIEV, 2001; VIGOTSKY, 2001; CHARLOT, 2000; LOMÔNACO, 2003; REIS, 2006)

Nesta mesma perspectiva Block afirma que a categoria sentido contribui para

avançar na superação da dicotomia de individuo e sociedade. Nesta perspectiva de análise o sujeito é reconhecido como ativo, participante do processo de compreensão, vivência e intervenção da realidade, ele não é nem reflexo do mundo social nem psicologicamente autônomo. Constrói sentidos e não faz isso de forma descolada da realidade, mas o faz exatamente porque se insere em uma realidade como um sujeito ativo, com todo seu conjunto de vivências, conhecimentos e emoções (BOCK, 2010, p. 
Bock acrescenta que "os sujeitos constroem sentidos a partir de suas vivências, do significado do discurso, da ideologia dominante e de suas necessidades" (2010, p. 44). A autora realiza estudos sobre a escolha profissional para classes pobres. Concordamos com o autor que parte do pressuposto de que

o sujeito escolhe e essa escolha é um momento de seu processo pessoal de construção de sentidos [...] Essa construção utiliza como recurso ou matéria prima não só a irredutível existência singular dos sujeitos, suas experiências e afetos que dedica a cada momento vivido, mas o conjunto de significações e de formas de relacionamento e de produção social em que acontecem e que circunscrevem as experiências vividas pelos sujeitos. A vida social na qual estão os determinantes importantes das escolhas profissionais, como a ideologia dominante, as formas de trabalho, o funcionamento do mercado, o papel da educação, os valores, os grupos de pertencimento, não é algo externo ao indivíduo (BOCK, 2010, p. 48).

Procuramos apreender os sentidos da escola e os planos de futuro em uma pesquisa de campo realizada em uma escola média situada nas proximidades da Universidade Federal de Alagoas, em um bairro periférico de Maceió.

De modo geral, pode-se identificar que $51 \%$ dos jovens que participaram do questionário respondido por cento e quinze jovens do período vespertino que estes têm entre 16 e 17 anos, que $29 \%$ têm entre 18 e 19 anos e que $19 \%$ têm entre 14 e 15 anos.. A maior parcela é do sexo feminino, $65 \%$ são mulheres e $35 \%$ são homens e que $16 \%$ deles trabalham. Parte dos jovens da tarde (66\%) possui renda familiar até R\$ 800,00. Para $23 \%$ destes jovens a renda é de $\mathrm{R} \$ 801,00$ a $\mathrm{R} \$ 1.100,00$, e apenas para $5 \%$ a renda familiar é maior que $\mathrm{R} \$ 1.500,00$. Mesmo a renda familiar não sendo 


\section{Juventudes no ensino médio: sentidos atribuídos à escola e aos planos de futuro.}

alta, identifica-se ainda que $34 \%$ dos participantes da pesquisa à tarde possuem computador em casa. A maioria que respondeu ao questionário utiliza internet para redes sociais $(84 \%)$, em segundo lugar para pesquisas escolares $(73 \%)$ e em terceiro lugar para MSN (45\%). Em relação às práticas culturais, os jovens citaram em primeiro lugar festas $(80 \%)$, em segundo lugar praia (69\%) e em terceiro lugar show $(44 \%)$.

Existem poucas possibilidades de lazer, atividades culturais para os jovens. Explicam que quando podem participam de festas familiares, religiosas, organizada por amigos e também, quando podem, frequentam as praias e, ainda, assistem televisão. Porém, explicam que temem a violência no bairro e não se sentem seguros para participar de poucos eventos promovidos nele. Portanto, para estes e estas jovens é na escola e na sala de aula que, geralmente, encontram os amigos, os colegas. Neste sentido, em relação aos espaços de estar com os amigos a maioria dos estudantes apontou a escola como lugar preferido, totalizando $83 \%$ das respostas. Isso pode sinalizar que apesar de possíveis dificuldades relacionadas à aprendizagem ou mesmo nas relações que ocorrem na escola, ela acaba se configurando na principal referência para eles.

Pode-se afirmar que a instituição escolar assume uma grande importância na vida destes jovens, importância esta que significa uma mobilização em relação a estar na escola, ao lugar deste espaço nas suas vidas, mas esta importância pode ou não relacionar-se às questões de mobilização em relação aos estudos. Essa importância da escola pode indicar, também, a ausência de acesso a outros espaços de sociabilidade onde vivem. Vale ressaltar, ainda, que muitos deles estão nesta escola, próxima de casa, desde o Ensino Fundamental. Se outros espaços de sociabilidade são remotos em suas vidas, é provável que os amigos e os grupos com os quais convivem sejam, na sua maioria, os colegas de escola.

Em relação à questão "se gostam da escola", os jovens responderam do seguinte modo: $82 \%$ dos alunos disseram gostar da escola. Este resultado sugere que a instituição escolar tem uma importância bastante positiva em suas vidas. Relativamente ao quesito "quando você pensa nos seus estudos", a maioria dos alunos da tarde, 98\%, escolhe a alternativa "são importantes para mim". Em seguida, aparece a alternativa "eu gosto de estudar", para 79\% dos alunos da tarde. Ressalta-se que uma parcela significativa dos estudantes, um terço do total de participantes - 39\% dos alunos da tarde admite ter dificuldades para estudar ao escolher a opção 
"mesmo que eu me esforce não vou bem".

Se a maioria afirma que gosta de estudar e que a escola é o lugar preferido para estar com os amigos, poderíamos supor que a maioria destes estudantes teria uma relação positiva com as atividades para apropriação dos saberes privilegiados pela escola. No entanto, outros resultados trazem elementos que permitem identificar uma relação contraditória com a escola e com os estudos. Em relação à contribuição da escola para a aprendizagem, dos cento e quinze estudantes da tarde que participaram do estudo exploratório, 61\% consideram que "a escola pouco contribui para a aprendizagem" e $4 \%$ que "não contribui nada". Ao somar estes percentuais, é possível verificar que $66 \%$ destes jovens consideram que a escola pouco ou nada contribui para sua aprendizagem, contra apenas $35 \%$ que disseram que a escola contribui muito para a aprendizagem.

Apesar de grande parte assinalar que gosta da escola, que os estudos são importantes e que a escola é um ambiente onde preferem encontrar com os amigos em detrimento de outros lugares, estes afirmam que a escola média pouco contribui para a aprendizagem escolar. "A mobilização para a escola não garante de todo uma mobilização na escola, isto é, um empenhamento verdadeiro na atividade escolar de apropriação de saberes" (CHARLOT, 2009a, p. 77).

Esta questão da importância dos aspectos relacionais na vida dos jovens é identificada, também, nos textos produzidos por eles. Foram escritos sessenta e dois balanços de saber pelos jovens do vespertino, trinta e três dos estudantes de uma sala do terceiro ano e vinte e nove de uma sala do segundo ano, para responder a insígnia "Desde que nasci aprendi muitas coisas; em casa, no bairro, na escola, em muitos lugares. O que ficou de mais importante? E agora, o que espero aprender?". No pósdoutorado que realizamos, sobre os desafios da mobilização em relação aos estudos para estes jovens, identificamos que

de modo geral, é possível identificar que $63 \%$ de aprendizagens evocadas nos textos se inserem naquelas arroladas nas aprendizagens relacionais e afetivas. Os $30 \%$ das aprendizagens descritas referem-se às aprendizagens intelectuais e escolares, sendo grande parte delas apresentadas como 


\section{Juventudes no ensino médio: sentidos atribuídos à escola e aos planos de futuro.}

expressões genéricas. Apenas $7 \%$ das aprendizagens evocadas relacionam-se às aprendizagens ligadas à vida. (REIS, 2012b, p. 47).

Nos textos, em relação "ao que esperam aprender", os estudantes do vespertino citam em primeiro lugar, em vinte quatro textos, as aprendizagens para a vida e para melhorar a si mesmo, em segundo lugar, em dezenove textos, as aprendizagens para ter um bom emprego e em terceiro lugar, aparece dez vezes a pretensão de entrar na universidade. Se somarmos a questão de ter um emprego e entrar na universidade o valor ultrapassa a questão das aprendizagens para a vida e para melhorar a si mesmo, em vinte e nove textos. Também dizem, em dez textos, que esperam aprender mais, de modo geral e há ainda para cinco estudantes da tarde aparece a crítica e desilusão com a escola em relação à promessa de ensiná-los. Identifica-se, portanto, que. se somarmos os resultados entrar na universidade e ter um emprego (29), este aspecto se apresenta como mais de $50 \%$ dos aspectos citados. Mesmo assim não se configura a maioria das respostas.

Em relação aos questionários respondidos por cento e quinze estudantes, quando indagados sobre a prioridade de formação no Ensino Médio, na visão de 51\% dos participantes da tarde, o Ensino Médio deve ter como prioridade formar para o ingresso no curso superior; $38 \%$ dos estudantes consideram que a prioridade é formar para o mercado de trabalho e $11 \%$ deles é desenvolver o sujeito como ser humano e cidadão. Observa-se que um percentual significativo apresenta como prioridade o Ensino Superior. Porém, há ainda $49 \%$ dos jovens da tarde que apresentam outras prioridades. Portanto, como em outros estudos, pode-se afirmar que para o conjunto dos estudantes, o Ensino Superior não é o único projeto vislumbrado com a escolarização no Ensino Médio. Nos questionários, os jovens do vespertino quando questionados sobre quem estaria ajudando em relação aos possíveis planos de futuro após o ensino médio, identifica-se que a família aparece com um expressivo primeiro lugar, sendo $64 \%$ das respostas, em seguida responderam que "ninguém" está ajudando com tais informações e apenas em terceiro lugar aparecem os professores e amigos, cada qual com $11 \%$ das respostas. Portanto, já nos questionários os resultados apontam para a questão de que a escola não discute com os jovens, questões relacionadas aos seus planos de futuro. 
Apresentamos a seguir a configuração dos estudantes que participaram do grupo de discussão do vespertino.

$3^{\text {o }}$ ANO - de 16 a 17 anos, dois rapazes e uma garota, todos solteiros, moram com os pais ou avós, não trabalham. As atividades de lazer citadas foram: praia, shopping, parque de diversão, eventos, namorar, jogar basquete. Em relação aos planos de futuro, Arquitetura, Engenharia Civil e Administração de Empresas.

$2^{\circ}$ ANO - de 15 a 17 anos, três mulheres e três rapazes, todos solteiros, todos moram com a família, não trabalham, um faz curso extracurricular, outra cita que faz afazeres domésticos. As atividades de lazer citadas foram: navegar na internet, cosplay, eventos, ir à Igreja, ir à praia, ouvir música, praticar esportes, ficar com a família. Sobre os planos de futuro foram citados cursos na universidade: Educação Física, Relação Internacional, Relações Públicas, Arquitetura, Jornalismo, Direito e um apenas citou que quer entrar na UFAL.

Para aqueles que participaram do grupo de discussão a prioridade também é prosseguir nos estudos e entrar no Ensino Superior. É importante ressaltar que identificamos, ao menos no período da tarde, que os professores escolheram os estudantes que mais se destacam nas aulas para a formação do grupo de discussão. Este aspecto e os argumentos de outros entrevistados indicam que os participantes do grupo de discussão e, posteriormente, uma parte deles como entrevistados não podem representar de modo significativo o conjunto dos estudantes no que se refere às expectativas em relação ao Ensino Médio, nem em relação às dificuldades para estudar. Provavelmente, eles fazem parte daqueles 51\% dos estudantes que têm como prioridade a entrada no Ensino Superior logo após o término do Ensino Médio. Também no grupo de discussão os jovens explicam que não há discussão na escola sobre os caminhos possíveis após o Ensino Médio, salvo o trabalho realizado por alguns professores, que comentam principalmente em relação ao que é necessário para prestar o Exame Nacional de Ensino Médio (ENEM). Estes jovens também consideram que sua formação no Ensino Médio não possibilitará a preparação para o ensino superior.

Se por um lado existem as críticas em relação à educação escolar recebida, há também o reconhecimento que precisariam estudar mais. A experiência escolar de boa parte dos jovens do vespertino é marcada pela 


\section{Juventudes no ensino médio: sentidos atribuídos à escola e aos planos de futuro.}

lógica dos estudos no Ensino Médio como uma obrigação para um futuro melhor que, muitas vezes não se sustenta, para além do discurso. Constatam que, mesmo após o ensino médio, poucas mudanças ocorrerão em suas vidas. Neste sentido, identifica-se que os planos de futuro, quando pensados, estão apartados da experiência na escola.

Sem espaços de diálogo sobre tal assunto, os sujeitos individualmente, com as poucas referências que possuem, buscam táticas, no sentido empregado por Certeau (2007), para pensar no futuro, mediante a realização de cursos extraescolares que aparecem e contando, às vezes, com o apoio da família e amigos. Os jovens do vespertino, que participaram do grupo de discussão realizam cursos extracurriculares e alguns, aqueles que se destacam nos estudos, têm acesso à Iniciação Científica na UFAL. Ao menos para aqueles que participaram do grupo de discussão identifica-se que há a expectativa entre eles de entrar no ensino superior logo após finalizar o ensino médio e até um incentivo dos pais de incentivarem a "moratória social breve", no sentido de tentar poupá-los da entrada no mercado de trabalho, tendo em vista uma tentativa de se preparar para o ensino superior. Eles apresentam sua escolha de profissões reconhecidas pela sociedade, como arquitetura, jornalismo, engenharia.

Este aspecto se diferencia do estudo de Bock (2010), em que doze jovens pobres, que terminaram o Ensino Médio e participavam de cursinho pró-universitário em um programa de orientação vocacional em uma ONG de São Paulo. Na referida pesquisa os jovens apresentaram como opção cursos superiores que não tinham tanto prestígio na sociedade. O autor explica que estes jovens vivenciaram tentativas de entrar no ensino superior em áreas mais procuradas, sem sucesso e, portanto, passaram a definir profissões nas quais teriam condições "conseguir" passar no vestibular (BOCK, 2010, p. 133). Ele também salienta que as profissões escolhidas são as mais próximas de suas vivências sociais. Apesar das diferenças entre o estudo de Bock e o nosso é possível identificar nas duas pesquisas que estas escolhas foram realizadas, geralmente, individualmente, no círculo familiar e de amigos e que, muitas vezes, não são acompanhadas de um conhecimento aprofundado sobre tais profissões escolhidas.

Esses resultados dialogam com outros estudos que apresentamos anteriormente e especialmente com uma pesquisa recente, realizada em 
escolas públicas de Ensino Médio do Estado do Pará, coordenada por Dayrell e Carrano, finalizado em 2010 e acessado pela internet em 2012. Apresentam um relatório com "os resultados da pesquisa Diálogos com o Ensino Médio, realizada em 2009 no âmbito uma cooperação técnica entre a Secretaria de Educação Básica, o Observatório Jovem da Universidade Federal Fluminense e o Observatório da Juventude da Universidade Federal de Minas Gerais." (2012, p. 4), realizado em escolas públicas do Pará, com doze grupos de diálogo com estudantes do terceiro ano do Ensino Médio, para discutir sobre seus projetos de vida. Ao analisar esta pesquisa Leão; Dayrell e Reis, explicam que

a ideia de projeto de vida remete a um plano de ação que um indivíduo se propõe a realizar em relação a alguma esfera de sua vida (profissional, escolar, afetivo.etc.) em um arco temporal mais ou menos largo. Tais elaborações dependem sempre de um campo de possibilidades dado pelo contexto socioeconômico e cultural no qual cada jovem se encontra inserido e que circunscreve suas experiências [...] falar em projeto e referir-se a uma determinada relação com o tempo, em especial o futuro, e especificamente as formas como a juventude lida com esta dimensão da realidade. (LEÃO; DAYRELL E REIS, 2011, p 1071-1072),

Nas análises das questões que surgiram nos grupos de diálogo com os estudantes do terceiro ano do Ensino Médio de escola públicas do Estado do Pará, os autores destacam algumas questões que dialogam com nossas preocupações de pesquisa. Explicam que a maioria quando aborda seus projetos futuros

refere-se à continuidade dos estudos através do ingresso no ensino superior, uma formulação majoritária dentre eles. Este fato em si já denota uma novidade desta nova geração de jovens que, diante da expansão do ensino médio e do ensino superior no Brasil, passam a colocar esta 
Juventudes no ensino médio: sentidos atribuídos à escola e aos planos de futuro.

perspectiva no seu horizonte de interesse, o que não ocorria na geração dos seus pais que, como vimos, apresentam uma escolaridade mais baixa do que a dos filhos [...] Temos de levar em consideração nas análises o peso do conjunto de representações sociais em torno do sucesso profissional, quase sempre associado ao sucesso escolar, o que pode naturalizar o desejo pela continuidade dos estudos, aparecendo como uma resposta "natural" ou óbvia. (DAYRELL e CARRANO, 2012, p. 75)

Identificam, ainda, que as posturas diante do futuro, com suas questões comuns e também diferenciadas, podem ser entendidas como

a busca de estratégias que os sujeitos constroem para lidar com o contexto em que vieram sendo formados e no qual se encontram, ou seja, o seu campo de possibilidades. Mas também com os recursos materiais e subjetivos a que tem acesso, à qualidade da sua trajetória escolar, incluindo ai o acesso ou não às informações sobre o universo do ensino superior e sobre o mundo do trabalho, dentre outras variáveis que interferem diretamente na capacidade de lidar com o futuro em um contexto social dominado pelas incertezas, [...] Significa dizer que os projetos de vida tendem a ser elaborados na medida da experimentação de si no contexto de um determinado campo de possibilidades, sem metas rígidas, em um processo de exploração marcado pela provisoriedade. (DAYRELL e CARRANO, 2012, p. 76)

De modo geral, nessa pesquisa identificou-se que os projetos de vida destes jovens tinham como horizonte a perspectiva a entrada na universidade, "como uma aposta nas promessas da modernidade" (LEÃO; DAYRELL E REIS, 2011, p. 1081). Apreendeu-se, ainda, que para os mais jovens, a escola se apresentava como lugar privilegiado para concretizar 
seus sonhos. Porém, expressavam muitas críticas aos limites da instituição escolar para prepará-los para concorrer de forma mais igualitária nos processos seletivos da universidade publica. Acrescentam os autores que a escola não vem possibilitando aos jovens uma compreensão da realidade na qual eles se inserem, uma visão sobre o mundo do trabalho e suas exigências, um conhecimento do que a universidade pode ou não oferecer, os cursos existentes com suas especificidades e demandas próprias. Explicam ainda que estes jovens não citam a escola em relação à orientação em relação aos seus projetos de futuro. Parecem abandonados à sorte e apenas citam o apoio da família.

Bock (2010) também, nas conclusões de seu estudo apresenta aspectos que se aproximam. Para ele há a necessidade das escolas médias incluírem a orientação profissional no seu currículo para propiciar aos estudantes não favorecidos economicamente a "cultura das profissões universitárias" (BOCK, 2010, p. 142).

Deste modo estes estudos estão em consonância com os aspectos identificados em nossa pesquisa. Também identificamos que os jovens do vespertino da escola de ensino médio em Maceió, apresentam a escola média como um lugar importante para suas vidas e possuem como perspectiva a entrada na universidade como promessa de um futuro melhor e tecem muitas críticas à escola, por considerar que esta não permite a preparação para realização deste objetivo. Eles não encontram na escola um espaço para refletir e discutir sobre as possibilidades a trilhar após terminar esta etapa de escolarização. Um aspecto que vale destacar é que em nosso estudo, apesar das críticas à escola, não demonstram que têm clareza de que tal escola poderia exercer esse papel.

\section{Considerações finais}

Concordamos com os documentos legais para o Ensino Médio que preconizam a ênfase na formação geral para os jovens, ultrapassando aquela dualidade entre educação propedêutica para as elites e educação profissional para os pobres (KUENZER, 2010). Estamos de acordo, também, com críticas realizadas no âmbito do sistema francês de ensino de que determinados programas para os jovens naquele país ao institucionalizar a construção de projetos de futuro acabavam induzindo 


\section{Juventudes no ensino médio: sentidos atribuídos à escola e aos planos}

de futuro.

esses jovens a seguir carreiras, consideradas mais adequadas de acordo com a origem social, o que seria enquadrá-los de acordo com as expectativas da sociedade que rotula e limita os jovens a se adequar às relações de poder e de dominação da sociedade (BIARNÈS, 1999).

Porém, identificamos que em nome de uma democratização do ensino que prepare para uma formação geral dos sujeitos, a instituição escolar de Ensino Médio recusa-se a enfrentar essa questão e, do nosso ponto de vista, acirra mais ainda a desigualdade de oportunidades dos jovens que dela fazem parte.

Nas pesquisas é possível identificar que os planos de futuro de jovens do Ensino Médio, quando pensados, estão apartados da experiência na escola. O que aprendem na escola pouco contribui para pensá-los e, portanto, quando questionados sobre quem mais estaria ajudando a pensar em seus planos de futuro, os jovens afirmam que contam em primeiro lugar com a família.

Sem espaços de diálogo sobre tal assunto, os sujeitos individualmente se sentem responsáveis pelas dificuldades que encontram. Com as poucas referências que possuem constroem seus planos de futuro sem compreender bem os caminhos possíveis para realizá-los. Consideramos, ainda, que os jovens das classes médias e altas partem em vantagem em relação aos suportes, redes sociais, informações para a construção de seus planos de futuro.

Como explica Bourdieu, os grupos menos favorecidos e suas famílias se sentem iludidos em relação ao discurso liberal que domina em nossa sociedade de que o aumento da escolarização poderia significar automaticamente uma melhoraria nas condições de vida. Estar na escola média não garante na atualidade aquele diploma que no passado era propiciado para uma elite e que assegurava o passaporte para melhores lugares na sociedade. Uma das consequências da expansão da escola pública no Brasil e de sua precariedade de qualidade seria "uma enorme crise das possibilidades de mobilização social ascendente via escola, a partir da desvalorização dos diplomas como propiciadores de credenciamento no mundo do trabalho e, portanto, pela criação de uma nova situação para as crianças e jovens, que se tornam "excluídos do interior"" (BOURDIEU, 1992 apud NOGUEIRA; CATANI, 1998, p. 224).

Estes jovens questionam o valor deste discurso de futuro melhor pelo diploma, mas ainda justificam através dele o sentido de passar boa 
parte da vida na escola. Por outro lado, para muitos jovens há desencontros entre os aspectos valorizados para enfrentar os desafios da vida e o tempo necessário para os estudos.

Concordamos com Charlot (2009b) quando afirma que muitas vezes as próprias práticas escolares não conseguem explicitar os desafios específicos de aprender na escola como objetos de pensamento.

Identificamos, em relatos dos estudantes, que, muitas vezes, as atividades para trabalhar esses saberes como modo de pensamento nas áreas específicas são veiculadas como resumos descontextualizados e que não permitem aos estudantes adentrarem nas suas lógicas. Se estes modos de pensamento não se conectam de alguma forma com as questões que fazem sobre si mesmos, os outros e o mundo podem reforçar a ideia de estar na escola apenas como obrigação, que concorre com outras demandas do presente.

Conforme Bauman (2008), a sociedade de produtores, modelo principal da fase sólida da modernidade, fundamentava-se na segurança estável, na estabilidade segura, na disciplina e na subordinação e se baseava na rotinização do comportamento individual. "A satisfação parecia de fato residir, acima de tudo, na promessa de segurança a [sic] longo prazo, não no desfrute imediato de prazeres" (2008, p. 43). Nesta sociedade, a escola que era para poucos, de certo modo cumpria seu discurso de progresso do sujeito a partir da escolarização, de trabalho escolar no tempo presente como preparação para um futuro promissor, para "ser alguém na vida". Aqueles que tivessem acesso aos patamares mais elevados de estudo tinham a certeza de que teria um bom emprego na sociedade.

Com a mudança de foco da sociedade, que coloca em primeiro plano o consumo, identifica-se a transformação da relação com o tempo. Este não é mais apreendido como cíclico ou linear, mas apresenta-se como "fragmentado, ou mesmo pulverizado numa multiplicidade de instantes eternos [...]. A vida, seja individual ou social, não passa de uma sucessão de presentes, uma coleção de instantes experimentados com intensidade variados" (2008, p. 46).

Como explica Bauman (2008), neste modo de compreender o mundo não se valoriza a noção de progresso, possibilitado pelos esforços humanos. "A ideia do tempo da necessidade foi substituída pelo conceito de tempo de possibilidades [...], aberto em qualquer momento" (2008, p.

Latitude, vol. 6, n¹, pp.131-155, 2012. 
Juventudes no ensino médio: sentidos atribuídos à escola e aos planos de futuro.

47) pela imprevisibilidade do novo. Portanto, o que importa é o momento presente, não perder a oportunidade, pois não haveria nova chance. Essa pressa é em parte justificada pelo impulso em adquirir coisas e pela necessidade de substituí-las e descartá-las (2008, p. 50).

Portanto, de acordo com Bauman (2008), essa sociedade está pautada no consumo, no presentismo, no aqui e agora, na compra da felicidade. Para serem reconhecidos pelos outros, os sujeitos devem fazer parte dessa lógica de consumo, sob o risco de serem ridicularizados e considerados menos capaz do que os outros. Nessa mesma perspectiva, a escolarização e o aprender passam a ser uma mercadoria como tantas outras. O conhecimento é valorizado em sua dimensão instrumental, para atender a essa demanda de consumo. Como explica Bauman, na sociedade contemporânea

lapsos de tempo rotulados de "futuro" encurtam, e a duração da vida como um todo é fatiada em episódios considerados "'um de cada vez' A continuidade não é mais marca de aperfeiçoamento. A natureza outrora cumulativa e de longo prazo do progresso está cedendo lugar a demandas dirigidas a cada episódio em separado: o mérito de cada episódio deve ser revelado e consumido inteiramente antes mesmo que ele termine e que o próximo comece. Numa vida guiada pelo preceito da flexibilidade, as estratégias e planos de vida só podem ser de curto prazo. (BAUMAN, 2001. p. 158)

Bauman explica ainda que nesta sociedade o trabalho não pode ser considerado garantido, como nos discursos do passado que relacionava a ampliação dos estudos como caminho capaz de assegurá-lo. Conforme o autor, "o trabalho escorregou do universo da construção da ordem e controle do futuro em direção do reino do jogo; atos de trabalho se parecem mais com as estratégias de um jogador que se põe modestos objetivos de curto prazo, não antecipando mais que um ou dois movimentos". (BAUMAN, 2001, p, 159)

Mesmo com tais transformações na sociedade, para alguns jovens a 
obtenção do diploma pode ser a única dimensão que mobiliza para os estudos. Para outros pode ser uma das dimensões importantes, havendo também outros motivos para estudar. De qualquer forma, estudar para ultrapassar os obstáculos e obter o diploma de Ensino Médio é um objetivo bastante valorizado pelos estudantes, mesmo que acompanhado de um sentimento de frustração por não garantir por si mesmo a possibilidade de apropriação de conhecimentos necessários para a continuidade nos estudos, para passar em concurso, dentre outras possibilidades.

Portanto, há contradições entre uma instituição que no discurso propõe os estudos como um futuro melhor, mas que se apresenta para os jovens como um período de "obrigações" que atrapalham a viver o presente.

Inserem-se nestas contradições a questão do lugar da escola na vida destes jovens. Se por um lado, a escola moderna é uma instituição burguesa que classifica e rotula as pessoas como mais ou menos capazes em nossa sociedade, a partir de um modo específico de se relacionar com o mundo, enquanto objeto de pensamento e que muitas vezes suas práticas se apresentam para os jovens como desprovidas de sentido capaz de mobilizá-los; por outro lado, consideramos que o acesso a essas lógicas de compreensão privilegiadas pela instituição escolar, nas suas diversas dimensões, pode contribuir, também, para que os sujeitos focalizem o mundo, os outros e a si mesmos por outros ângulos, não de maneira passiva, mas de modo crítico (REIS, 2012).

Não é objetivo aqui aprofundar estas questões, porém consideramos que é necessário levar em consideração estas contradições quando pensamos o lugar da escola na sociedade contemporânea. Esta escola somente pode fazer sentido para os jovens se de algum modo proporcionar espaços para que possam compreender melhor essa sociedade atual e compartilhar suas angústias em relação a como enfrentar os desafios neste mundo complexo, o que inclui pensar, também, nos modos de construir seus planos de futuro.

Compartilhamos os questionamentos apresentados em outras pesquisas sobre a necessidade de se pensar na possibilidade de espaços de diálogo com os jovens desfavorecidos economicamente na escola média para que estes tenham condições de articular o que aprendem nesta etapa de escolarização com a construção de possíveis táticas e estratégias para 
Juventudes no ensino médio: sentidos atribuídos à escola e aos planos de futuro.

viabilizar seus planos de futuro.

Em razão das contradições apresentadas, resta-nos terminar este texto e provisoriamente essas reflexões com algumas questões. Qual o tipo de contribuição a escola média pode propiciar para as juventudes não favorecidas economicamente? Ela pretende contribuir para a formação destes sujeitos em que sentido? Quais os limites e possibilidades para jovens não favorecidos economicamente desta escola média, em nossa sociedade capitalista atual? Reconhecer estas juventudes não seria também escutar suas necessidades e angústias em relação as suas incertezas sobre como viabilizar seus planos futuros, numa sociedade em que as relações entre presente e futuro se tornam cada vez mais complexas e pouco evidentes?

\section{Referências}

ABRAMO, H. W. Considerações sobre a tematização social da juventude no Brasil. Revista brasileira de educação Mai/Jun/Jul/Ago 1997 № 5 Set/Out/Nov/Dez 1997, p.25-36.

ABRAMO, H. W. Condição juvenil no Brasil contemporâneo. In: ABRAMO, H. W.; BRANCO, P. P. Retratos da Juventude Brasileira: análises de uma pesquisa nacional. São Paulo: Ed. Fundação Perseu Abramo; Instituto Cidadania, 2005.

BAUMAN, Zygmunt. Vida para consumo: a transformação das pessoas em mercadoria. Rio de Janeiro: Zahar, 2008.

BAUMAN, Zygmunt. Trabalho. In: Modernidade Líquida. Rio de Janeiro: Zahar, 2001.

BIARNÈS, Jean. Universalité, diversité e sujet dans l'espace pédagogique. Paris: L'Harmattan, 1999.

BOURDIEU, P. Excluídos do interior. In: NOGUEIRA, M. A.; CATANI, A. Escritos de Educação. [S.1.:s.n.], 1998.

BOCK, Silvio Duarte. Orientação Profissional para as classes populares. São Paulo: Cortez, 2010.

CERTEAU, Michel de. A invenção do cotidiano. 1. Artes de Fazer. Petrópolis. Rio de Janeiro: Vozes, 2007.

CHARLOT, Bernard. Relação com o saber e com a escola entre estudantes 


\section{Rosemeire Reis}

de periferia. Cadernos de Pesquisa, São Paulo, n. 97, p. 47-63, maio 1996.

CHARLOT, B. (Org.). Os jovens e o saber: perspectivas mundiais. Porto Alegre: Artmed Editora, 2001.

CHARLOT, B. Da relação com o saber: elementos para uma teoria. Porto Alegre: Artmed Editora, 2000.

CHARLOT, B. A relação com o saber nos meios populares: uma investigação nos Liceus profissionais no subúrbio. Portugal: Legis Editora, 2009a

CHARLOT, B. A escola e o trabalho dos alunos. Sísifo, Revista de Ciências da Educação, n.10, p. 89-96, 2009b

CORTI, F.; FREITAS, M. V.; SPOSITO, M. O encontro das culturas juvenis com a escola. São Paulo: Ação Educativa, 2001.

DAYRELL, Juarez. O jovem como sujeito social. Revista Brasileira de Educação. 2003, no 24, set/out/nov/dez.

DAYRELL, Juarez. A escola "faz" as juventudes? Reflexões em torno da socialização juvenil. In: Educação e Sociedade. Campinas, vol.28, n.100Especial, p.1105-1128, out.2007.

DAYRELL, Juarez. Juventude e Escolarização: os sentidos do Ensino Médio. TV Escola, Salto para o futuro: Secretaria da Educação a distância, Ministério da Educação, ano XIX, boletim 18, 2009.

DAYRELL, J. T; CARRANO, P. C. R. Relatório final da pesquisa "Diálogos com o Ensino Médio": Observatório da Juventude (UFMG); Observatório Jovem (UFF): Ministério da Educação (MEC). Disponível em http://www.emdialogo.uff.br/materia/pesquisa-di\%C3\%A1logos-com-oensino-m\%C3\%A9dio-relat\%C3\%B3rio-final. Acessado em 02 de julho de 2012

DUBET, F.; MARTUCCELLI, D. À'école: sociologie de l'expérience scolaire. Paris : Seuil, 1997.

KUENZER, Acácia Zeneida,(org.) Ensino médio: construindo uma proposta para os que vivem do trabalho. São Paulo: Cortez, 2000

LEÃO, G; DAYRELL, J. T.; REIS, J. B. Juventude, Projetos de vida e Ensino Médio. Educ. Soc., Campinas, v. 32, n. 117, p. 1067-1084, out.-dez. 2011

LOMÔNACO, B. A relação com o saber de alunos da zona rural de um município da Serra da Mantiqueira. São Paulo: Faculdade de Educação, Universidade de São Paulo, 2003. 105p. Relatório de pós-doutorado. Supervisão de Leandro de Lajonquière.

LEONTIEV, A. N. (Org.). Linguagem, desenvolvimento e aprendizagem. São Paulo: Ícone, 2001.

Latitude, vol. 6, n¹, pp.131-155, 2012. 
Juventudes no ensino médio: sentidos atribuídos à escola e aos planos de futuro.

MANZANO, Cinthia Soares. A escuta ao aluno do Ensino Médio: ampliando o olhar sobre o jovem e o adolescente. 2004. 78p. Monografia (Trabalho de conclusão de curso em Educação). Faculdade de Educação, Universidade de São Paulo, 2004

MARGULIS, Mario e URRESTI, Marcelo. La construcción social de la condición de juventud. Disponível em:

http://www.perio.unlp.edu.ar/catedras/system/files/mario_margulis_y_ma rcelo_urresti_-

_la_construccion_social_de_la_condicion_de_juventud_urresti.pdf.

Acessado em dezembro de 2012. PAIS, José Machado. Culturas Juvenis.

Lisboa: Impressa Nacional - Casa da Moeda, 2003

PERALVA, A. O jovem como modelo cultural. Revista Brasileira de Educação. p. 15-24. Mai/Jun/Jul/Ago , no 5, 1997Set/Out/Nov/Dez no 6,1997

PAIS, José Machado. Culturas Juvenis. Lisboa: Impressa Nacional - Casa da Moeda, 2003

REIS, Rosemeire. Encontros e Desencontros: a relação de jovens/alunos do Ensino Médio com os saberes escolares. 203p. Tese (Doutorado em Educação). Faculdade de Educação, Universidade de São Paulo, 2006.

REIS, Rosemeire. Experiência escolar de jovens/alunos do ensino médio: os sentidos atribuídos à escola e aos estudos. Educação e Pesquisa, São Paulo, v. 38, n. 03, p. 637-652, jul./set. 2012a.

REIS, Rosemeire. Processos de mobilização e/ou de desmobilização em relação aos estudos para jovens e adultos no Ensino Médio. Relatório final de pesquisa. Supervisor: Prof. Dr. Bernard Charlot. Pós-Doutorado em Educação, na Universidade Federal de Sergipe (UFS), 2012b.

SANTOS, Cleber N. Políticas da Educação a Distância no Ensino Superior: o foco no aluno do Sistema UAB/UFAL. Maceió: UFAL, 2011. 315 f. Dissertação (Mestrado em Educação). Programa de Pós-Graduação em Educação Brasileira, Centro de Educação, Universidade Federal de Alagoas, Maceió, 2011.

WELLER, Wivian. Grupos de discussão na pesquisa com adolescentes e jovens: aportes teórico-metodológicos e análise de uma experiência com o método. Educação e Pesquisa, São Paulo, v.32, n.2, , maio/ago, p. 241-260, 2006.

VIGOTSKI, L. S. Aprendizagem e Desenvolvimento Intelectual na Idade Escolar. In: VIGOTSKI, L. S.; LURIA, A. R.; LEONTIEV, A. N. (Org.). Linguagem, desenvolvimento aprendizagem. São Paulo: Ícone, 2001. 
Rosemeire Reis

SPOSITO, Marília P.; GALVÃO, Izabel. A experiência e as percepções de jovens na vida escolar na encruzilhada das aprendizagens: o conhecimento, a indisciplina, a violência. Perspectiva - Revista do Centro de Ciências da Educação da UFSC, Florianópolis, v. 22, n. 2, p. 345-380, 2004 a.

SPOSITO, M. (Des)encontros entre os jovens e a escola. In: (org.) FRIGOTTO, G.; CiAVATTA, M. Ensino Médio: ciência, cultura e trabalho. Brasília: Secretaria da Educação Média e Tecnológica/MEC/SEMTEC, $2004 \mathrm{~b}$

VAN ZANTEN, Agnès. L'école de la périphérie: scolarité et ségrégation en banlieue. Paris: Presses Universitaires de France, 2001.

Latitude, vol. 6, n¹, pp.131-155, 2012. 